\title{
Frameless stereotaxy in a transmandibular, circumglossal, retropharyngeal cervical decompression in a Klippel-Feil patient: technical note
}

Daniel M. Sciubba · Ira M. Garonzik · Ian Suk •

Gary L. Gallia · Anthony Tufaro · Jean Paul Wolinsky •

Alex Taghva $\cdot$ Ziya L. Gokaslan

Published online: 23 October 2007

(c) Springer-Verlag 2007

Erratum to: Eur Spine J (2006) 15:1286-1291

DOI 10.1007/s00586-006-0092-1

The original version of this article unfortunately contained a mistake. Alex Taghva was not listed among the authors. The correct order is as follows:
Daniel M. Sciubba · Ira M. Garonzik · Ian Suk · Gary L. Gallia · Anthony Tufaro · Jean Paul Wolinsky · Alex Taghva · Ziya L. Gokaslan

The online version of the original article can be found under doi:10.1007/s00586-006-0092-1.

D. M. Sciubba · I. M. Garonzik - I. Suk ·

G. L. Gallia · J. P. Wolinsky · A. Taghva · Z. L. Gokaslan (ه)

Department of Neurosurgery, Johns Hopkins School

of Medicine, 600 North Wolfe Street, Meyer 7-109,

Baltimore, MD 21287, USA

e-mail: zgokas11@jhmi.edu

\section{A. Tufaro}

Department of Plastic Surgery,

Johns Hopkins School of Medicine,

Baltimore, MD, USA 